\title{
A Brief Talk about the Application and Expression of Floor Decoration Art in Interior Design
}

\author{
Y. P. YANG, Y. L. MA \\ Faculty of Art and Communication, Kun Ming University of Science and Technology, Kunming, 650093, \\ China
}

\begin{abstract}
The internal space bottom interface, which is the basic element of indoor surrounding space, needs to meet the demands of not only basic activities but also peoples' spiritual enjoyment with the development of construction technology and the improvement of people's view of beauty. By studying the decorative elements of various indoor floors, we can conclude that artistic atmosphere of the defined space is determined by visual features of floor design under the conditions of basic functions such as support, safety, endurance, beauty and so on.
\end{abstract}

KEYWORD: Indoor floor; Decorative element; Artistic atmosphere; Floor design

\section{INTRODUCTION}

There is no space without interface. As one of the most fundamental interfaces of interior decorative design and the platform of supporting indoor activities and the furniture, the floor design affects the function and use of the whole space even affects the expression effect and style characteristic of spatial form. In order to meet peoples pursue for comfort, science and art of floor design. A full consideration of peoples age, character, body and psychological characteristics is necessary, the designer must choose and design based on peoples' needs for functional requirements and visual atmosphere of the floor. So, it is especially important to pay attention to forms, materials, color, lights and patterns of indoor floor as well as barrier-free design.

\section{SHAPES OF INDOOR GROUND}

The design of indoor ground is a comprehensive content that contains both technology and art. The floors' formative form, as the supporting surface, can intuitively create a rich spatial form with certain functional requirements. So, special formative form appears at ground shape of some big space or space with special requirements. Lifting ground and sunken ground are the most common grounds.

Partial indoor ground lifts. The chosen area from the lifted edge to the inside forms the lifting ground what makes space type has the function of emphasis and display. As opposed to lifting, the chosen area below surrounding space forms sunken ground. No matter the sunken ground or the lifting ground, both of them have the function of certain limits and involve the change of height, what make the space more interesting and the space variation richer.

\section{THE SELECTION OF INDOOR GROUND MATERIALS}

Decoration material, which is the fundamental element of reflecting ground design, not only has the decorative destination but also is the important part of interior design. We should know the structure, color, mechanics, texture, light sensation, decoration performance of various materials and decorative material processing. It requires strictly on art, use, economy, environment, psychology, decoration and the select of materials.

First, the material decoration performance plays an important role in the change of indoor ground design on the decoration and art point of view. Under the premise of meeting peoples' use, formal beauty and artistic beauty are the further requirements. Second, from a practical application point of view, when we conduct a ground design, the ground materials should have some physical chemistry and mechanical properties and need to be beautiful, endurance and friction resisting. Third, from the economical point of view, we need to consider the cost of the project and choose different prices of materials based on different decoration 
standards. Fourth, from the environment point of view, environmental protection property must be emphasized when we choose the ground materials. Last, from the psychology point of view, it should meet peoples' spiritual enjoyment according to different places and different requirements after meeting the requirements of human engineering.

\section{SPECIES OF GROUND DECORATION MATERIALS}

There are many kinds of decoration materials. The common materials used for indoor ground design in the modern interior design are as follows, stone floor, tile floor, wooden floor, rubber floor, glass floor, plastic floor, coating floor etc.

\subsection{Stone floor}

Stone ground, which has wear resistance, corrosion resistance and special patterns, texture, color, gloss, belongs to the hard ground. We choose the suitable stones based on utilization frequency of different space floors and wearing life of materials when we design. Granite, marble, quartzite, basalt, sandstone etc have a good artistic performance in indoor ground design.

\subsection{Tile floor}

Tile floor has many types, mainly including glazed tile, polished tile, vitrified tile, titanium and so on. The tile has many specifications, patterns, colors and textures. It is widely used in indoor ground design.

\subsection{Wooden floor}

Wooden floor has the best shaping property. The floor can be designed to many styles such as flower shape, pinwheel shape etc. It is not only environmental-friendly but also has many materials such as solid wood floor, laminate floor, plywood and so on.

\subsection{Rubber floor}

Rubber floor has the properties of elastic, skid-proof, antistatic etc. Man-made material, what can be made into various colors and the surface can be made into fluctuating patterns which has a certain decorative meaning, is suitable for laboratories, transport internal, museums etc. For example, indoor floor of library and metro is that case.

\subsection{Glass floor}

Glass floor has an empty and transparent texture that is deeply loved by people today. The use of glass plays an important role in creating indoor environment. For indoor floor design, glass and metal materials are often used at the same time to ensure the safety and beautiful. According to the property of glass, no matter with the modern metal or the pristine texture of wood it has a unique style of expression which can improve the space quality.

\subsection{Plastic floor}

Today in indoor ground design, plastic can often imitate the decorative effect of wood, marble etc. It has a property of reducing noise, uneasy cracking, light, easy moving, uneasy-molding and so on. In indoor ground, not only it can be decorated into transparent and translucent beacon but also we can use the transmittance to create a ground decoration atmosphere and to get the effect of lighting.

\subsection{Coating floor}

Said coating, we will think of the wall painting. With the development of science and technology, special coatings can be used to decorate the ground. It is a special coating which is used to brush the cement ground and floor board. The coating often has a property of wear-resisting, corrosion resistant, water proof, oil proof and so on.

\section{THE APPLICATION OF DECORATIVE COLORS AND LINGHT IN INDOOR GROUND}

Color has certain temperature sense, distance sense, weight sense, dimension sense and space sense in the physical effect and has eye-pleasing sense, mixed feeling and character sense in the psychological effect. Different space art effects can be created through the application of colors' hue, lightness and chroma in indoor ground design. Light, what can change the color of the ground, is the decoration element of ground design. For different ground styles, it's very important about how to influence the color of indoor objects and ground.

\subsection{The guidance of color}

Color, which is the design element in ground decoration, has a certain guidance effect. For example, we can use floor tile and transparent material, both of what have the same color of different lightness, to present visually a ground with strong sequence guidance pattern

\subsection{Creating atmosphere and building artistic effect}

Compared to other ground decoration elements, color is easier to create the room atmosphere. 
Different indoor atmospheres can be created based on the difference that material reflects and refracts differently on the light. Some formal occasions such as the conference room, the negotiating room etc usually apply neutral color scheme to render a quiet atmosphere.

\subsection{Strengthen the sense of space and three- dimension}

The sense of space and three-dimension is strengthened by the skillful match of color and light. Especially when the color and light are concentrated on area with different height, variety and contrasts will appear. Foiling interior space sense of rhythm and inspiring the enthusiasm of people in order to make the spatial contrast fiercer and more interesting.

\section{DECORATION PATTERN AND SCALE OF INDOOR GROUND}

Ground patterns can provide a visual center for the space. When we are designing the ground patterns, we need to coordinate the ceiling, wall decoration and interior furnishing. In addition, the ground can be the leading element of interior space through its paving styles. Using decoration elements such as ground color, pattern, size and texture etc to constitute an ordered geometric network or abstract pattern based on the principle of formal beauty of interior design.

\subsection{Grid ground pattern}

The size of floor tile has different influences when the bedroom area is different. We design different patterns based on different requirements. For example, floor of both herringbone and grid patterns are effective methods that can be used to emphasize a long space or a strip space.

\subsection{Ground pattern of a guidance quality}

Any continuous element in ground style will become the leading factor. Directional paving style can often influence the ground visual proportion relationship and we can increase or reduce the sense of dimensions in a certain direction. When it coordinate with the changes of ceiling plane or the expected furniture group, it will play a guidance role invisibly and become more influential. For example, in a large hotel or shopping mall the ground pattern design is often eye-attracting, which plays a guidance role invisibly and balances peoples' visual focus of the whole space.

\subsection{Abstract ground pattern}

The scope of the pattern is very wide in the design of ground pattern. The abstract pattern designed based on the formal beauty principle will seem more unique. Abstract patterns have a certain property such as randomness, flexibility, liveliness and innovativeness. The ground pattern design will often create ground paving based on expected interior furnishing in the art gallery, coffee shop etc. Of course, ground pattern can be freewheeling design and even random splash of paint of different colors can have unexpected decoration effect.

\section{CONCLUSION}

By this token, the ground pavement can provide a visual center. Even it can provide a middle element, what can contact with other ground designs, to make the whole space have a sense of sequence. No matter what spatial organizations, all should start from the principle of formal beauty under the premise of meeting human engineering. A comprehensive consideration of basic requirements such as ground shape, material, color, light, pattern and barrier-free design is needed. Using various design methods flexibly to ensure the implementation of the design. Making full use of factors of positive expression for ground design, excluding negative factors at the same time, to improve space and render atmosphere then the ground design can be well used and expressed in different space atmospheres.

\section{REFERENCES}

[1] Q. J. Wang. Interior design. Beijing: Mechani cal industry press, 2007:234

[2] J. H. Hu Generality on the interior design. Beijin g: China forestry press, 2009: 95-109

[3] D. M. Cheng. Interior design illustrated. Tianjin: Tianjin University press, 2010: 276

[4] B. L. Shen. 1000 questions of interior design. Beijing: Mechanical industry press, 2012: 169

[5] D. H. Cui. The conspectus of interior design. Bei jing: Peking University press, 2007: 243- 251

[6] S. H. Zhang. Generality on the interior design. Wuhan: Huazhong University of Science and Technology press, 2009: 69-273

[7] B. L. Shen. Interior design element set. Beijing: China architecture industry press, 2013

[8] Y. Chen. Principles of interior design. Beijing: China architecture industry press, 2006: 270- 281

[9] Y. F. Xin. Indoor environment design of construc tion. Beijing: Mechanical industry press, 2006: 175-182 